\title{
Transcatheter Arterial Embolisation of Acute Nonvariceal Upper Gastrointestinal Bleeding Refractory to Endoscopic Haemostasis
}

\author{
JH Kwon, JS Kim \\ Department of Radiology, Dongguk University Ilsan Hospital, Goyang-si, Republic of Korea
}

\begin{abstract}
Upper gastrointestinal tract bleeding (UGIB) originates in the distal oesophagus, stomach, and duodenum (proximal to the ligament of Treitz). The most common cause of nonvariceal UGIB is peptic ulcer disease, but it is associated with many different diagnoses, including benign and malignant tumours, ischaemia, gastritis, arteriovenous malformations such as Dieulafoy's lesions, Mallory-Weiss tears, trauma, and iatrogenic causes. Endoscopic haemostasis remains the initial treatment modality, but when endoscopic treatment fails to control bleeding, transcatheter arterial embolisation is a safe, effective, and minimally invasive treatment compared with surgery. Advances in catheterbased techniques and embolic agents have expanded the role of interventional radiology in UGIB treatment. This article discusses the aetiologies of UGIB, methods of embolisation, characteristics of embolic agents, and evidence in the literature regarding the technical and clinical outcomes of transcatheter arterial embolisation in patients with acute nonvariceal UGIB.
\end{abstract}

Key Words: Angiography; Embolization, therapeutic; Gastrointestinal hemorrhage

\section{中文摘要}

\section{經內鏡止血困難時以經導管動脈栓塞治理急性非靜脈曲張上消化道出血}

\author{
JH Kwon, JS Kim
}

\begin{abstract}
上消化道出血源於食道遠端、胃和十二指腸（Treitz勒帶近端十二指腸）。非曲張性上消化道出血的 最常見原因為消化性潰瘍, 其他原因包括良性和惡性腫瘤、缺血、胃炎、動靜脈畸形（如Dieulafoy 病灶、賁門粘膜撕裂、創傷和醫源性原因）。內鏡止血仍然是初步治療方式。然而, 當內窺鏡治療 無法控制出血時, 與手術相比, 經導管動脈栓塞術是一種安全有效且微創的治療方法。基於導管的
\end{abstract}

Correspondence: Prof JH Kwon, Department of Radiology, Dongguk University Ilsan Hospital, Goyang-si, Republic of Korea Email:jhkwon17@naver.com

Submitted: 6 Aug 2018; Accepted: 21 Aug 2018

Contributors: JHK contributed to the concept of study, acquisition and analysis of data, and wrote the manuscript. All authors had critical revision of the manuscript for important intellectual content. All authors had full access to the data, contributed to the study, approved the final version for publication, and take responsibility for its accuracy and integrity.

Conflicts of Interest: The authors declare that there is no conflict of interest.

Funding/Support: The authors received no financial support for the research, authorship, and/or publication of this article.

Ethics Approval: This study was approved by the institutional review board of Dongguk University Ilsan Hospital (Ref 2016-33). The requirement for informed consent was waived for inclusion in this retrospective study. 


\section{技術和栓塞劑的進步加強了介入放射學在上消化道出血治療中的作用。本文討論上消化道出血的病 因、栓塞方法、栓塞劑的特性以及有關急性非靜脈曲張上消化道出血患者進行經導管動脈栓塞的技 術及臨床結果的文獻資料。}

\section{INTRODUCTION}

Upper gastrointestinal (GI) bleeding (UGIB) is defined as bleeding originating in the distal oesophagus, stomach, and duodenum (proximal to the ligament of Treitz). Upper GI bleeding is 5 times more common than lower GI bleeding. This distinction is important, as localisation of the bleeding source determines the therapeutic approach. ${ }^{1-3}$ The most common cause of nonvariceal UGIB is peptic ulcer disease. Other less common causes include benign and malignant tumours, ischaemia, gastritis, Mallory-Weiss tears, trauma, iatrogenic factors, and arteriovenous malformations such as Dieulafoy's lesions. ${ }^{4,5}$

Effective treatment requires an accurate diagnosis including the location and aetiology. Unlike the case with lower GI bleeding, most patients have undergone endoscopic examination and treatment before being referred for interventional radiology. ${ }^{6}$ However, endoscopic evaluation and potential treatment are sometimes not technically feasible because of oesophageal strictures, altered anatomy from prior surgery, or profuse bleeding. ${ }^{3}$ Of the small group of patients whose bleeding fails to respond to endoscopic therapy, some are treated surgically, but the majority have been increasingly referred for transcatheter arterial embolisation (TAE). ${ }^{6}$ Surgical treatment is typically reserved for patients whose bleeding has failed to respond to all previous treatments. In such cases, conservative surgical techniques that focus on the source of the bleeding are usually preferred to conventional surgery. ${ }^{6}$ The development of newer catheter techniques and embolic devices over the last three decades has made percutaneous TAE the standard management technique for UGIB in patients with unfeasible or failed endoscopic management of bleeding., ${ }^{3,6}$ The purpose of this review is to summarise the data on the aetiologies, indications, techniques, and outcomes of TAE for acute nonvariceal UGIB.

\section{CAUSES OF ACUTE NONVARICEAL UPPER GASTROINTESTINAL BLEEDING}

Erosive processes, such as peptic ulcers, oesophagitis, gastritis, duodenitis, and Zollinger-Ellison syndrome, account for $70 \%$ of UGIB cases. ${ }^{6-8}$ The incidence of bleeding from these complications among elderly patients has increased because of improved life expectancy and the expanded use of nonsteroidal anti-inflammatory drugs. ${ }^{8}$ Cyclooxygenase- 2 inhibitors, which are used for both their anti-inflammatory and analgesic properties, are associated with an overall increased use of nonsteroidal anti-inflammatory medications and subsequent UGIB. ${ }^{9}$ GI bleeding can be accelerated if a patient is in an endogenous coagulopathic state or on anticoagulation therapy. ${ }^{6}$

Oesophageal varices are the second most common cause of UGIB, accounting for $5 \%$ to $14 \%$ of cases. ${ }^{10}$ These patients present with portal hypertension and may have underlying alcoholic liver disease or hepatitis-induced cirrhosis. ${ }^{8}$ However, the management of oesophageal varices and portal hypertension is generally distinct from the conditions described herein and is excluded from this review.

A Mallory-Weiss tear is a mucosal laceration at the gastroesophageal junction or in the cardia region of the stomach. ${ }^{11}$ These lesions are associated with repeated retching or vomiting and are another important cause of nonvariceal UGIB. It is estimated that $5 \%$ to $15 \%$ of all cases of acute UGIB are secondary to Mallory-Weiss tears. ${ }^{11,12}$

Dieulafoy's lesion is characterised by a large aberrant arteriole in the mucosa that has the potential to rupture spontaneously. ${ }^{13}$ It is a calibre-persistent gastric artery or aneurysm and may be considered as an aberrant large arteriole. These arterioles, which are approximately $1 \mathrm{~mm}$ in diameter, can reach the submucosa and invade through the mucosal surface. ${ }^{13,14}$ Dieulafoy's lesion is relatively rare and is thought to cause fewer than $5 \%$ of all cases of GIB.?

Both malignant and benign neoplasms involving or originating from the upper GI tract may cause $2 \%$ to $5 \%$ of cases of UGIB. Although only a small proportion of UGIB cases are of neoplastic aetiology, UGIB may be the only presenting symptom of a neoplasm and therefore should be included in the differential diagnosis. ${ }^{6,7}$ 
Vascular ectasias, also referred to as angiomas, arteriovenous malformations, and angiodysplasia, are another source of UGIB. Angiodysplasia or arteriovenous malformations are vascular anomalies characterised by an abnormal tangle of vessels with a prominent draining vein or veins that typically exhibit early and prolonged opacification. ${ }^{7}$ These vascular anomalies are seen more frequently in lower GI bleeding but also occur rarely in UGIB. ${ }^{15}$

Other rare causes of nonvariceal UGIB should also be considered in any differential diagnosis. Aortoenteric fistula is a rare but potentially catastrophic cause of UGIB. Communication between the aorta and bowel can develop from pathologic processes at either site. The most common causes of aortoenteric fistula are aortic aneurysm, infectious aortitis due to syphilis or tuberculosis, and surgical repair of an abdominal aortic aneurysm; surgical intervention is necessary in almost all such cases, as mortality without surgical intervention has been reported to be as high as $100 \%{ }^{6,7,16}$ Haemobilia, a pathologic process of the liver or recent hepatobiliary tree instrumentation, is another rare cause of UGIB that should be considered in trauma and surgery settings. ${ }^{6,8,17}$ Haemosuccus pancreaticus refers to bleeding from the pancreatic duct and should be considered in patients with chronic pancreatitis or pseudocysts. Bleeding in these patients can be secondary to a pseudoaneurysm in peripancreatic blood vessels as a complication of pancreatic pseudocysts. ${ }^{18}$ Finally, iatrogenic injuries secondary to biopsies or endoscopic procedures, such as the placement of percutaneous endoscopic gastrostomy tubes, are also rare but potential causes of nonvariceal UGIB..$^{4,18}$

\section{INDICATIONS FOR ANGIOGRAPHY}

Since TAE was introduced as an alternative to surgery for control of UGIB, embolotherapy has become a useful diagnostic and therapeutic tool in selected patients. ${ }^{19}$ The typical candidate patient presents with the following: (1) massive bleeding (transfusion requirement of at least $4 \mathrm{U}$ blood in $24 \mathrm{~h}$ ) or haemodynamic instability (hypotension with systolic pressure $<100 \mathrm{mmHg}$ and heart rate $>100$ beats/min or clinical shock secondary to blood loss), (2) bleeding that has failed to respond to conservative medical therapy, including volume replacement, antacids, $\mathrm{H} 2$ receptor blocking agents, or proton pump inhibitors, and (3) bleeding that has failed to respond to at least one, and sometimes two, attempts at endoscopic control. ${ }^{6,20}$ At that point, low-risk patients are offered the option of surgical intervention, whereas high-risk patients are offered TAE. Finally, TAE can be used after open surgical intervention has failed and bleeding has recurred, even after percutaneous embolotherapy ${ }^{6,21}$ It is important to perform angiography while the patient is bleeding, rather than waiting until the patient is hypotensive or unstable..$^{22}$

\section{CONTRA-INDICATIONS TO ANGIOGRAPHY}

There are no absolute contra-indications to angiography and embolisation, as these can be lifesaving procedures. Thus, contra-indications to TAE in patients with UGIB are only relative. These include renal insufficiency, contrast allergy, and uncorrectable coagulopathy. For patients with severe reactions to iodinated contrast media, alternative contrast agents such as carbon dioxide can be used. There is an increased risk of gastric or duodenal infarction following TAE in patients who have received previous extensive upper GI surgery or radiotherapy ${ }^{6,21,23,24}$

\section{DIAGNOSTIC EVALUATION}

Successful treatment of UGIB depends on accurate initial assessment of the patient's condition and on prompt localisation of the bleeding site. Upper endoscopy is the initial diagnostic modality of choice for acute UGIB. ${ }^{10}$ It is highly accurate at determining a diagnosis and is very useful for formulating treatment strategies and therapeutic interventions. ${ }^{25}$ The sensitivity and specificity of endoscopy have been reported as $92 \%$ to $98 \%$ and $33 \%$ to $100 \%$, respectively. ${ }^{8}$ Endoscopy can also help with planning the timing of and approach to angiography. ${ }^{24}$ For example, the ability to find the source of bleeding helps to guide the choice of which artery to cannulate first during angiography. Endoscopic information, such as excluding oesophageal bleeding sources, is valuable to angiographers. ${ }^{24}$ Nevertheless, endoscopy may miss up to $10 \%$ of lesions if they are within the reach of the endoscope and $18 \%$ if they are out of reach. ${ }^{26}$

Technical improvements in multidetector computed tomography (MDCT) technology, such as higher temporal resolution, have expanded the application of CT angiography for evaluating patients with vascular disease, including acute GI bleeding. ${ }^{27}$ Temporally resolved MDCT angiography allows the identification of active extravasation of contrast material and accurate identification of the source of haemorrhage. ${ }^{27}$ MDCT angiography is a rapid and easy-to-perform diagnostic method for fast and accurate detection and localisation of acute GI bleeding in the emergency setting. ${ }^{27,28}$ The 
sensitivity of MDCT angiography for diagnosing the source of GI bleeding has been reported as $91 \%$ to $92 \%$ and $45 \%$ to $47 \%$ for active and obscure GI bleeding, respectively. ${ }^{28,29}$

Scintigraphy and enteroscopy using technetium 99m-labelled red blood cells or technetium 99m-sulfur colloid, as well as video capsule endoscopy, are not universally accessible in the emergency setting. ${ }^{27}$ Scintigraphy imaging has advantages including its non-invasiveness and its ability to image for long periods of time. Its disadvantages include difficulty determining the precise location of the site of bleeding. Generally, scintigraphy plays a minor role in UGIB diagnosis because upper endoscopy has a high accuracy rate for detection of UGIB. ${ }^{8}$

\section{ANGIOGRAPHY AND EMBOLISATION Angiography}

By the time a patient with UGIB reaches the interventional room, fluid resuscitation and correction of coagulopathy should have been initiated. Blood products such as packed red blood cells, fresh frozen plasma, or platelets may also be given intraoperatively. ${ }^{4,23}$ Bladder catheter insertion is desirable. ${ }^{23}$ During the procedure, blood pressure, heart rate, oxygen saturation, and electrocardiogram are monitored. It is desirable to have anaesthesiologist and intensive care physician support, particularly with patients who are haemodynamically unstable. ${ }^{23}$ It is desirable to correct any coagulopathy prior to embolisation because achieving haemostasis depends on both technically successful embolisation and the patient's ability to form a clot. However, angiography with embolisation should be promptly performed in patients who are acutely bleeding, followed by coagulopathy correction. ${ }^{6}$ Endoscopic diagnosis and therapy can render angiography unnecessary or inform the timing or planning of the angiographic approach. Even negative endoscopic information, including exclusion of oesophageal bleeding, is particularly valuable to angiographers. ${ }^{24}$ Increased time to angiography is a predictor of early re-bleeding after embolisation; therefore, angiography and embolisation should be performed soon after the onset of bleeding. ${ }^{30,31}$

Angiography is used most often when endoscopy fails to detect UGIB. The main goals of angiography are to (1) accurately confirm the diagnosis of bleeding, (2) accurately localise the site of bleeding, and (3) provide transcatheter therapy as required. ${ }^{8}$ Angiography is very specific (100\% specificity) and highly sensitive (90\% sensitivity) for UGIB ${ }^{8}$ It was used successfully to detect bleeding in a canine model when the rate of bleeding was $>0.5 \mathrm{~mL} / \mathrm{min}$, and in-vitro studies have suggested that digital subtraction angiography is five- to nine-fold more sensitive than film-screen angiography for detecting haemorrhage. ${ }^{8,32}$ One definitive sign of GI bleeding in angiography is extravasation of contrast medium into the bowel lumen (Figure 1). ${ }^{8,22}$ Indirect signs of GI bleeding include aneurysm/pseudoaneurysm, arteriovenous fistula, vessel

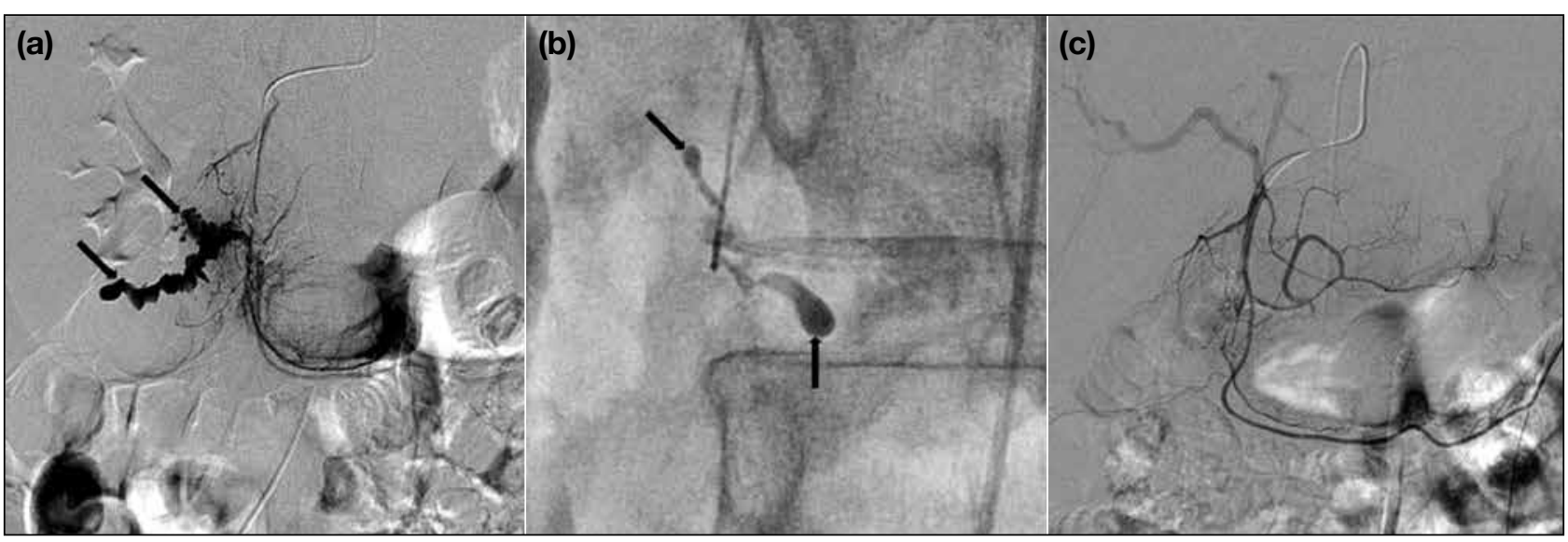

Figure 1. A 49-year-old female patient after failed endoscopic haemostasis of a bleeding duodenal ulcer. Bleeding had stopped after sustained haematochezia 2 days post-embolotherapy. However, the patient died 10 days after embolisation due to cardiogenic shock following myocardial infarction. (a) Superselective microcatheter angiography within a pancreaticoduodenal arcade (PDA) showing active contrast extravasation (arrows) into the duodenal lumen. (b) Injection of an N-butyl-2-cyanoacrylate mixture (NBCA:lipiodol = 1:2; arrows) via a microcatheter for bleeding from a branch of the PDA. (c) Post-embolisation angiography of the gastroduodenal artery showing no residual contrast extravasation. 
irregularity, vessel cut-off, hyperaemia, or neovascularity on imaging (Figure 2), ${ }^{8,22}$ Interventionists should recognise digital subtraction artefacts in angiograms that mimic contrast extravasation, such as bowel peristalsis and adrenal gland blush. ${ }^{7}$

In the majority of cases, transfemoral arterial access is used for initial catheter introduction. Abdominal aortography is generally unnecessary, as it requires a large bolus of contrast medium and has a low likelihood of identifying active bleeding. ${ }^{7}$ Glucagon and scopolamine butylbromide may be given before the procedure to decrease bowel motility and motion artefacts during digital subtraction angiography. ${ }^{21}$ The first vessels selected for angiography should be determined following an accurate history and clinical exam and guided by $\mathrm{CT}$, scintigraphic images, or endoscopic findings. ${ }^{21}$ In patients with UGIB, the celiac and superior mesenteric arteries are the main target vessels. If routine angiography of the celiac artery or superior mesenteric artery does not identify a bleeding focus, superselective catheterisation of the smaller branches should be performed. Angiographic images should be obtained until the venous phase has cleared out to distinguish contrast extravasation from venous opacification..$^{21}$ If the bleeding site is still not identified by angiography, the bleeding site may be small and therefore difficult to visualise, or the offending bleeding vessel may not have been catheterised. ${ }^{8}$ When two bleeding sources are suspected, both arterial sources need to be embolised to assure that all inflow ceases. This is typically seen when an ulcer invades into the gastroduodenal artery. ${ }^{6,24}$

The use of carbon dioxide as a contrast medium can improve angiography's sensitivity for small bleeds. ${ }^{6,22}$ Endoscopic clips placed around the bleeding area to achieve pre-embolisation endoscopic haemostasis can help to accurately localise the site of bleeding. If no extravasation is seen despite contrast injection, then the branches terminating at the clip are superselected and embolised using microcatheter techniques. ${ }^{33,34}$ Provocative angiography following infusion of tolazoline (a vasodilator), heparin, or thrombolytics such as tissue plasminogen activator can encourage bleeding. However, not enough data are available to generate definitive guidelines for performing provocative mesenteric angiography or pharmacoangiography. ${ }^{24}$ Those techniques are mainly used to induce lower GI bleeding, which is more challenging to localise than UGIB. Most UGIB cases require endoscopy to identify, localise, and treat the source of bleeding. Several prior studies have shown that in the absence of contrast extravasation, empiric embolisation based on endoscopic findings can be performed safely and successfully. ${ }^{24,35}$ The absence of contrast extravasation in angiography is less problematic in the upper GI tract and does not prevent embolisation of the artery supplying the bleeding site..$^{24}$

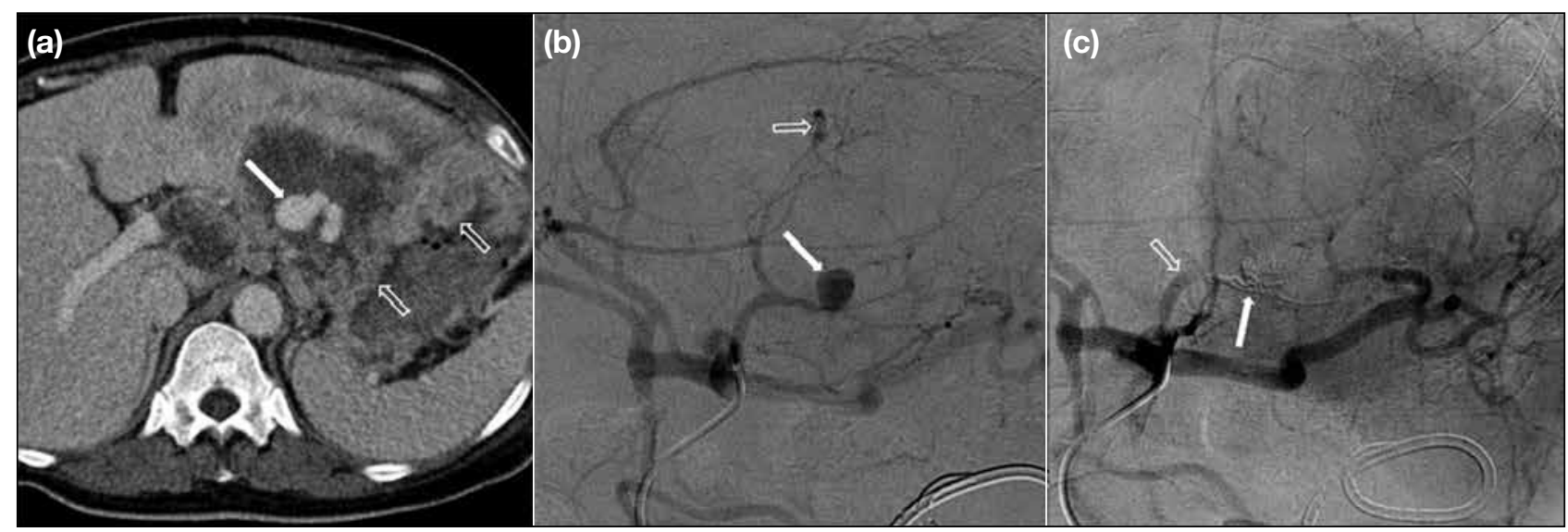

Figure 2. A 59-year-old female patient presenting with upper gastrointestinal bleeding associated with liver metastasis from a primary gastric malignancy. Bleeding had been controlled, and the patient had recovered following embolisation of the left gastric artery (LGA). (a) Axial image of a contrast-enhanced computed tomography scan showing active contrast extravasation (arrow) within the metastatic lesion in the liver. A mass lesion (open arrows) involving the gastric wall is noted. (b) Angiography of the celiac trunk showing a pseudoaneurysm (arrow) originating from the LGA and irregularities (open arrow) of the distal branch of the LGA. (c) Angiography of the celiac trunk after embolisation of the pseudoaneurysm and supplying branch of the LGA with an N-butyl-2-cyanoacrylate mixture (NBCA:lipiodol = 1:2) showing casting of the NBCA (arrow) and the obstructed LGA (open arrow). Distal branch of the LGA showing irregularities embolised by Gelfoam particles. 


\section{Embolisation}

The goal of TAE is selective reduction of blood flow at the bleeding source while maintaining sufficient collateral flow for intestinal viability. ${ }^{7,24}$ Despite the fact that vessel embolisation carries some risk of bowel ischaemia or infarction, selective catheterisation and precise embolisation minimise these complications. ${ }^{7}$ In addition, the GI tract has a rich collateral blood supply with extensive vascular arcades that allow safe embolisation. ${ }^{7}$ Contemporary TAE techniques generally involve the placement of diagnostic 4- to 5-French catheters into the main trunk of the feeding artery, followed by coaxial introduction of a 3-French or smaller microcatheter. The microcatheter can then be used to superselectively catheterise the target vessel as close as possible to the source of bleeding. It therefore must have an internal diameter that allows introduction of the chosen embolic agent. ${ }^{3,7}$

Embolisation can be classified as localised, proximal, or segmental. ${ }^{21}$ In localised embolisation, superselective embolisation at the site of bleeding is performed without embolising other non-target arteries (Figure 3). Proximal embolisation is required when a microcatheter cannot enter the bleeding vessel and embolisation must be performed in its parent artery, leaving the actual bleeding site without embolisation (Figure 4). With proximal embolisation, recanalisation of the bleeding artery can occur as a result of distal back flow. Segmental embolisation is the inclusion of an adjacent branch artery or arteries in addition to the segment responsible for the bleeding (Figure 5). With excessive segmental embolisation, ischaemic complications of the involved bowel can occur.

Many embolic agents have been used successfully, including coils, microcoils, gelatine sponge particular materials, polyvinyl alcohols (PVA), and trisacryl gelatin particles. Liquid embolic materials such as N-butyl-2-cyanoacrylate (NBCA) or ethylene-vinyl copolymer (Onyx; Microtherapeutics, Inc., Irvine [CA], United States) are less frequently used..$^{6,24,30,36-38}$ There is still debate about which embolic material is ideal. Embolotherapy needs to be performed quickly, feasibly, and effectively in emergency cases. Each embolic material has particular advantages and disadvantages, and the choice of embolic material is usually made based on bleeding location, aetiology, and operator preference. ${ }^{3,4,24}$

Coils are used for the embolisation of macroscopic vessels and must be used cautiously and precisely as they permanently occlude the bleeding vessel (Figure 6). Embolisation of UGIB using coils acts to decrease arterial pressure in the involved vascular bed, resulting in a more effective clotting cascade and reduction of bleeding. ${ }^{4}$ Particulate agents can be used together with coils to embolise distal vessels. The main advantage of coils is the lower risk of ischaemic complications, as they are used for focal occlusion of macroscopic arteries, whereas the more distal microvasculature is maintained
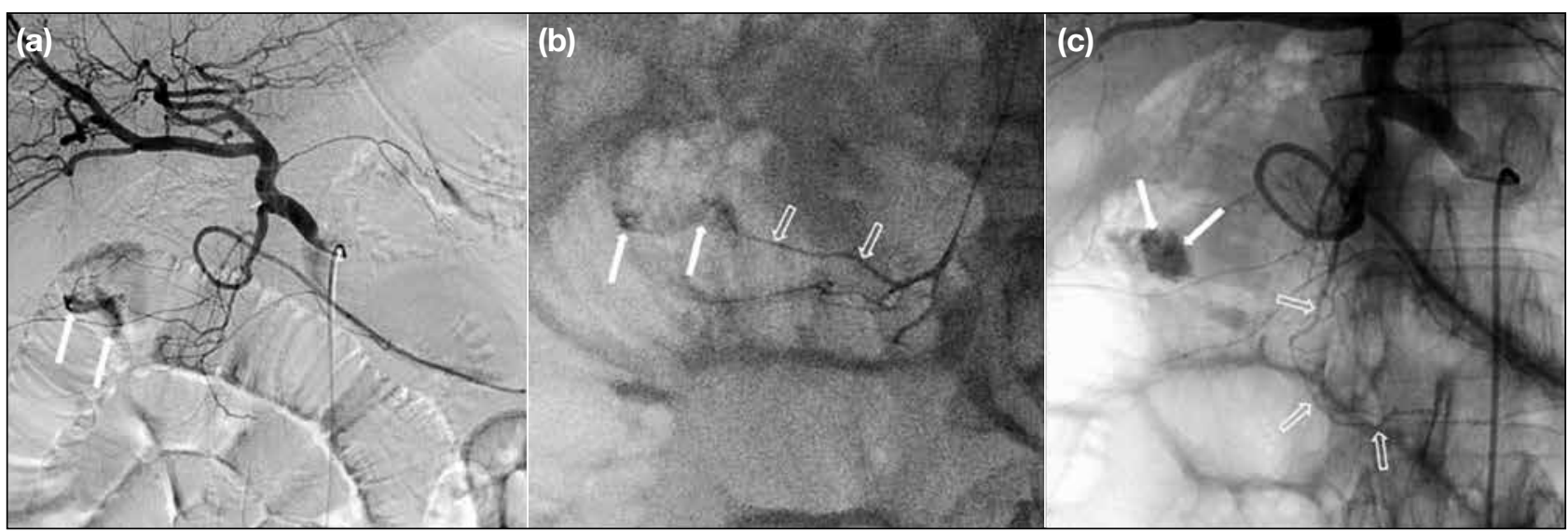

Figure 3. A 63-year-old male patient with melena during an inpatient stay for septic shock. After failed endoscopic haemostasis, the bleeding was controlled with embolisation. However, the patient passed away as a result of septic shock 3 days after the procedure. (a) Common hepatic artery $(\mathrm{CHA})$ angiography shows active contrast extravasation (arrows) from a branch of a pancreaticoduodenal arcade (PDA). (b) Contrast injection via a microcatheter shows contrast extravasation (arrows) following superselection of the supplying branch (open arrows) at the bleeding site. (c) Angiography of the $\mathrm{CHA}$ after embolisation of a branch of the PDA with N-butyl-2-cyanoacrylate (NBCA:lipiodol = 1:2) showing no active contrast extravasation and a well-preserved PDA (open arrows). Casting of the NBCA mixture (arrows) is noted in the duodenal lumen. 


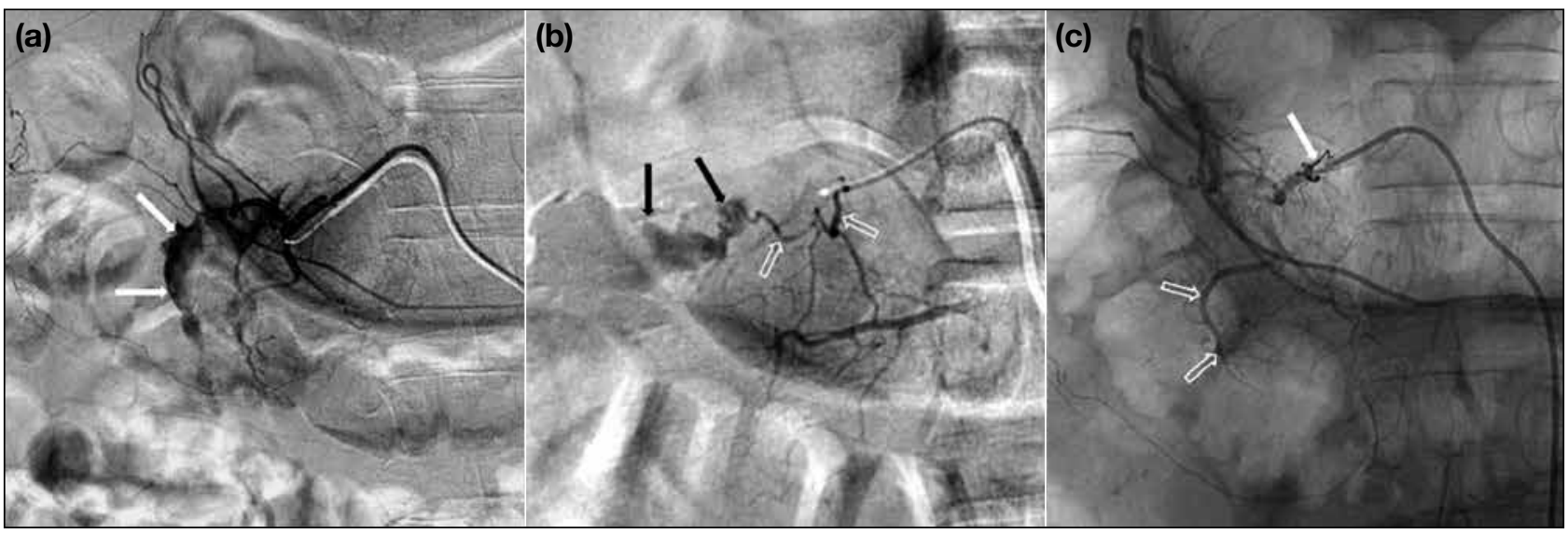

Figure 4. A 59-year-old male patient following failed endoscopic haemostasis of a bleeding duodenal ulcer. Bleeding was controlled with embolisation, and the patient was discharged. (a) Angiography of the gastroduodenal artery showing active contrast extravasation (arrows) into the duodenal lumen. (b) Selective angiography of a supplying branch (open arrows) of a pancreaticoduodenal arcade (PDA) at the site of bleeding shows active contrast extravasation (arrows). (c) Angiography of the common hepatic artery after embolisation of the supplying branch using microcoils (arrow) at the proximal portion of the branch showing no contrast extravasation and a relatively well-preserved PDA (open arrows). The microcatheter could not be advanced any further because of the tortuosity of the vessel.

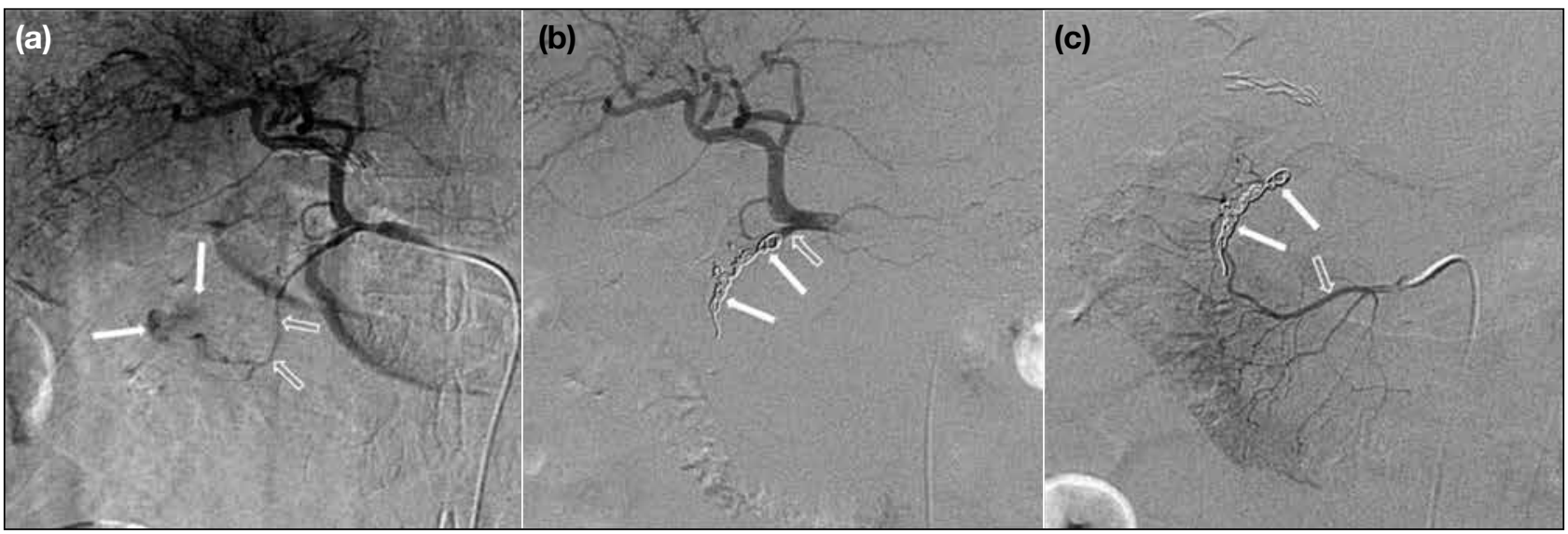

Figure 5. A 68-year-old male patient with haematemesis following endoscopic sphincterotomy for a common bile duct stone in the ampulla of Vater. Bleeding was controlled with embolisation, but the patient died 7 days later due to exacerbated acute respiratory distress syndrome, pulmonary oedema, and septic shock. (a) Angiography of the common hepatic artery (CHA) showing active contrast extravasation (arrows) into the duodenum from a pancreaticoduodenal arcade (PDA; open arrows). (b) Angiography of the CHA after embolisation of the PDA and gastroduodenal artery (GDA) using microcoils (arrows) showing no residual contrast extravasation and an obstructed GDA (open arrow). (c) Angiography of the inferior PDA (open arrow) of the superior mesenteric artery shows no contrast extravasation from collateral vessels. The microcoils (arrows) used for embolisation of the PDA and GDA are visible.

through collateral circulation. Coils can be placed more precisely than can liquid agents, which are more difficult to control. ${ }^{1}$ The main disadvantage of coils is that they occlude the artery permanently and preclude re-intervention if further embolotherapy is required. ${ }^{4}$

Gelatine sponges are one of the oldest flow-directed embolic agents (Figure 7). Reduction in pressure proximal to the bleeding site using sponges can be sufficient to stop the bleeding. ${ }^{4}$ Gelatine sponges are biodegradable and re-absorbable, allowing recanalisation of embolised vessels 2 to 6 weeks postoperatively. ${ }^{3}$ The advantages of Gelfoam particles are that they are readily available, inexpensive, and unlikely to cause ischaemia, allowing future access to embolised vessels after re-absorption. ${ }^{3}$ The disadvantages include the time-consuming preparation of appropriately sized particles and the unpredictable pace of recanalisation..$^{1,4}$ 

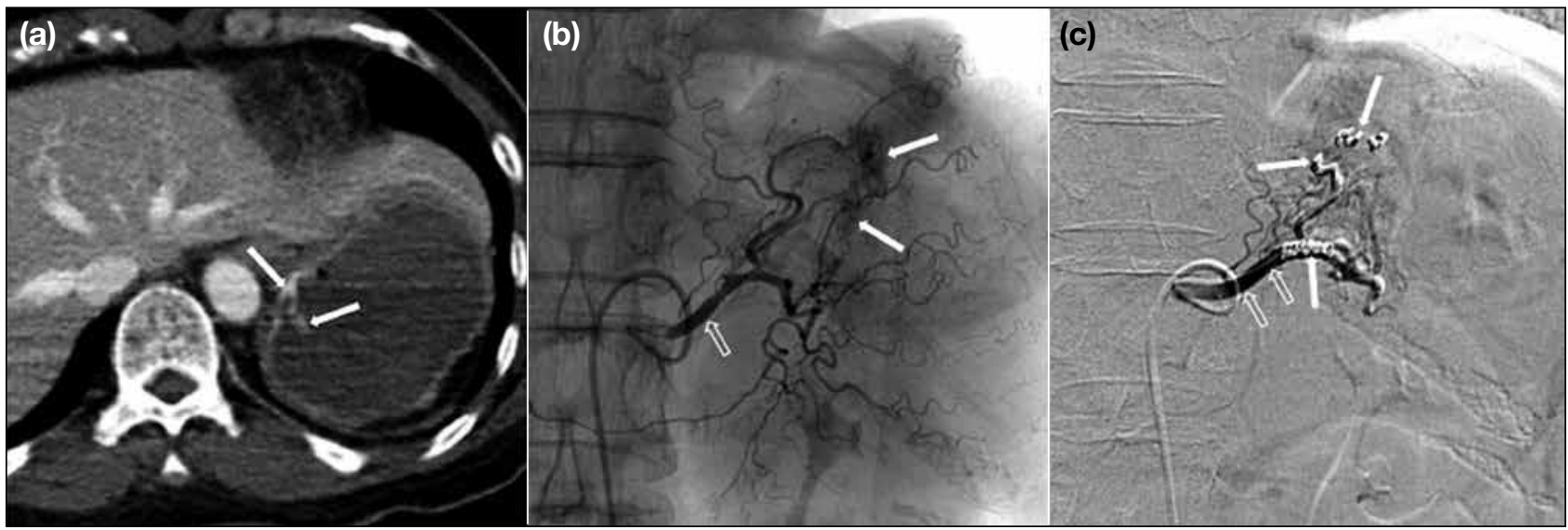

Figure 6. A 57-year-old female presenting with hematemesis following a Mallory-Weiss tear. The patient was discharged 1 week after embolisation with controlled bleeding and recovered vital signs. (a) Axial image of contrast-enhanced computed tomography showing active contrast extravasation (arrows) at the gastric cardia. (b) Selective angiography of the left gastric artery (LGA; open arrow) showing active contrast extravasation (arrows) at the gastric cardia and fundus. (c) Angiography of the LGA after embolisation of the main trunk and branches of the LGA using microcoils (arrows) showing occlusion of the LGA (open arrows) with no active contrast extravasation.
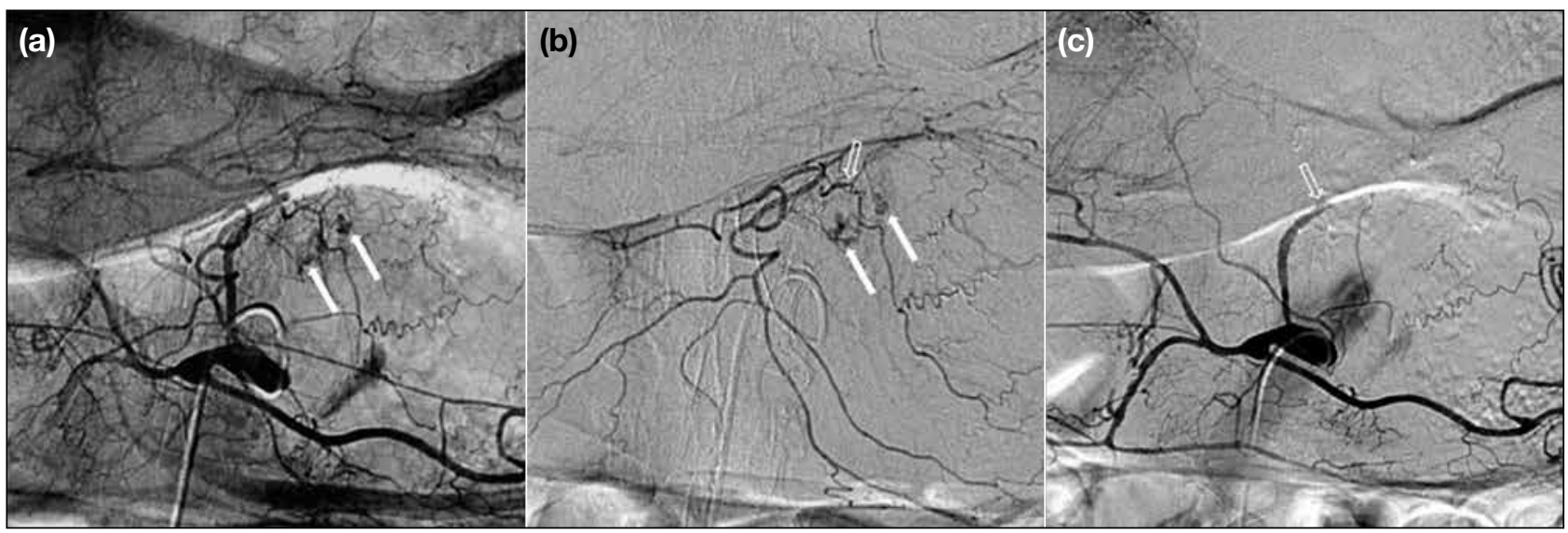

Figure 7. An 86-year-old female patient with a bleeding gastric ulcer. The patient was taking antithrombotic and anticoagulant medications for secondary prevention of cardiovascular and cerebrovascular disease. Bleeding stopped following Gelfoam embolisation of the left gastric artery (LGA), and the patient was discharged without any ischaemic complications. (a) Angiography of the celiac trunk showing active contrast extravasation (arrows) from the LGA. (b) Selective angiography of the LGA showing contrast extravasation (arrows) from a branch (open arrow) supplying the lesser curvature of the stomach body. The main trunk and proximal branches of the LGA were embolised using Gelfoam particles. (c) Celiac trunk angiography after embolisation of the LGA with Gelfoam particles showing an occluded LGA (open arrow) at the proximal trunk with no residual contrast extravasation.

Lang et $\mathrm{al}^{39}$ reported that a higher rate of re-bleeding in UGIB was noted when gelatine sponges were used alone than in combination with other embolic agents. Encarnacion et $\mathrm{a}^{40}$ reported a low success rate in their study, which included patients embolised with gelatine sponges alone, suggesting that the use of gelatine sponges as the only embolic agent assures only short-term results and should be avoided. ${ }^{24}$ Recently, premade and precisely calibrated gelatine sponge particles (Caligel; Hangzhou Alicon Pharm Sci \& Tec Co., Zhejiang,
China) have become available, and these do not require time-consuming preparation and are more predictable in size. Large pledgets of gelatin sponges created by cutting individual sponge pieces can also be used as torpedoes to occlude larger vessels. ${ }^{4}$ In addition, gelatine powder is also commercially available as an embolic agent, but it results in higher incidence of ischaemic complications. ${ }^{4}$

Particles of PVA vary in size and are supplied as either irregular or spherical particles suspended in sterile 
saline. ${ }^{3}$ They are inexpensive and easy to use but have a similar precision to that of coils (Figure 8). The particles are mixed with contrast medium immediately before injection. Their irregular surface may cause clumping or aggregation of particles, resulting in catheter obstruction or large vessel occlusion. ${ }^{41}$ The use of PVA particles is reserved for areas where permanent embolisation down to the arteriolar bed is required in the bleeding lesion. These agents have been used successfully to treat GI bleeding. Usually, larger particles $(>500 \mu \mathrm{m})$ are used to decrease the risk of ischaemic complications. ${ }^{3,4,24}$

The main liquid embolic agents include dehydrated ethanol and NBCA. Dehydrated ethanol, which is cytotoxic, is generally used to induce necrosis throughout the entire vascular bed. The use of dehydrated ethanol is reserved for treatment of arteriovenous malformations. ${ }^{4}$ NBCA is mixed with an oily contrast medium (Lipiodol; Guerbet, Aulnay-sous-Bois, France) to make it visible and viscous, and it polymerises upon contact with circulating ions. Depending on the volume and solubility of the dilutional agent, the material can be designed to solidify rapidly or more gradually. ${ }^{4}$ Embolisation by NBCA is quick and permanent, with the degree of embolisation controlled by titrating the viscosity of the mixture. Embolisation with NBCA can be useful in haemodynamically unstable patients and in cases of underlying coagulopathy.$^{24}$ Recently, good results using
NBCA to control GI bleeding have been reported. ${ }^{42-45}$ Embolisation using NBCA is effective in cases with involvement of fine and tortuous vessels, which are difficult to embolise using coils. The embolisation of both feeding arteries and collateral vessels is often too difficult and time-consuming to catheterise selectively (Figure 9) ${ }^{45}$ The main disadvantage of NBCA is that reflux of even small amounts of NBCA can result in non-target embolisation and complete occlusion of a non-target vessel. ${ }^{4}$ The use of NBCA requires training and considerable experience to prevent bowel ischaemia or infarction caused by reflux of NBCA into non-target vessels. $^{24}$

Because of the often intermittent nature of GI bleeding, the incidence of normal angiographic findings in patients with acute UGIB and lower GI bleeding has been observed as $52 \% .{ }^{46}$ If the site of bleeding is not identified, empiric embolisation is an alternative that can be guided by endoscopic evidence. ${ }^{22}$ Empiric embolisation for UGIB is sometimes encouraged because GI bleeding is often intermittent and accompanied by high re-bleeding and mortality rates if left untreated. Angiographic confirmation of a bleeding site is not a prerequisite for TAE in UGIB. Several studies have shown no differences in clinical outcomes between patients with negative and positive angiographic findings after TAE. ${ }^{47-49}$ In the case of gastric bleeding that is visible on endoscopy, the left gastric artery is often embolised (Figure 10).

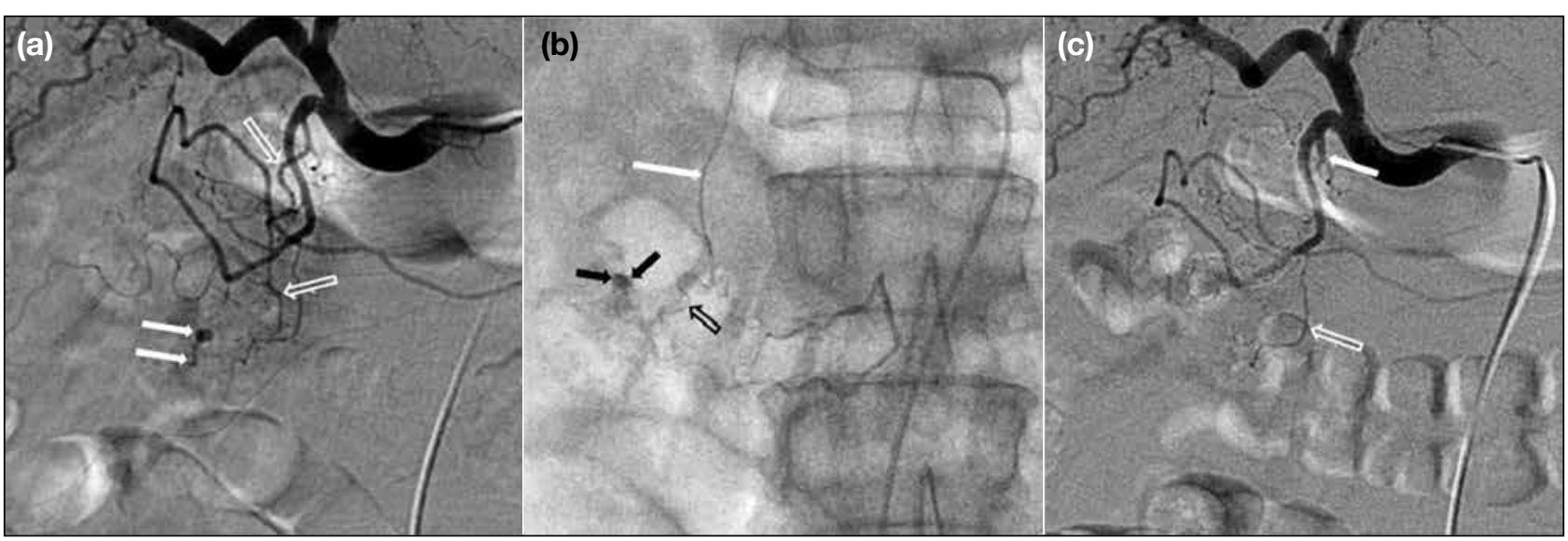

Figure 8. A 57-year-old female patient with a bleeding duodenal ulcer. The patient was discharged after the bleeding was controlled following polyvinyl alcohols (PVA) embolisation without ischaemic complications. (a) Angiography of the common hepatic artery (CHA) showing contrast extravasation (arrows) from a pancreaticoduodenal arcade (PDA; open arrows). (b) Image following superselection using a microcatheter (white arrow) showing contrast extravasation (black arrows) from a supplying branch (black open arrow) of the PDA. PVA (500-700 $\mu \mathrm{m}$ size) particle embolisation was performed for the PDA via a microcatheter. (c) Angiography of the CHA after PVA embolisation showing a proximally occluded PDA (arrow) with no residual contrast extravasation. A non-embolised PDA filled with contrast is also shown (open arrow). 


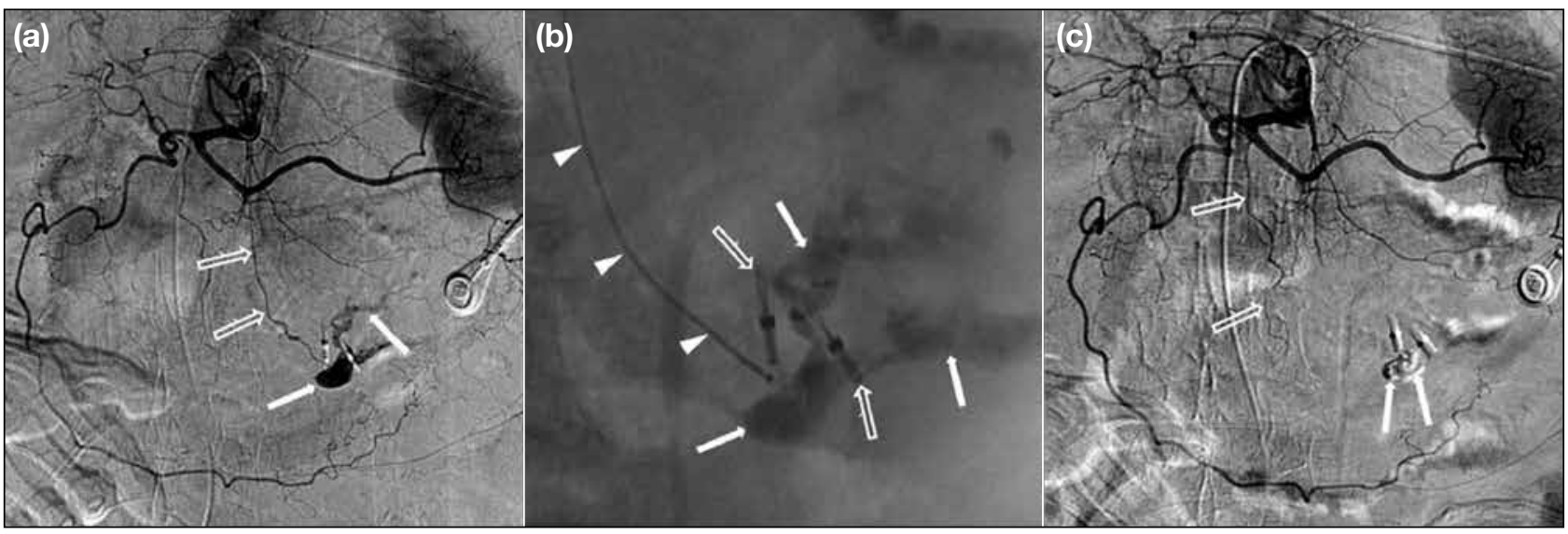

Figure 9. An 84-year-old male patient following failed endoscopic haemostasis and clipping of a bleeding gastric ulcer. Gastrointestinal bleeding was controlled with N-butyl-2-cyanoacrylate (NBCA) embolisation, but the patient died from worsened acute respiratory distress syndrome 2 weeks post-embolisation. (a) Angiography of the celiac trunk showing active contrast extravasation (arrows) from a branch (open arrows) of the left gastric artery (LGA) into the stomach. (b) An image taken after superselective catheterisation using a microcatheter (arrow heads) showing contrast extravasation (arrows) and endoscopic haemoclips (open arrows). The bleeding branch of the LGA was selectively embolised using an NBCA mixture (NBCA:lipiodol = 1:1). (c) Angiography of the celiac trunk after NBCA embolisation showing occlusion of the bleeding branch (open arrows) of the LGA and casting of the NBCA (arrows). Contrast extravasation ceased following embolisation.

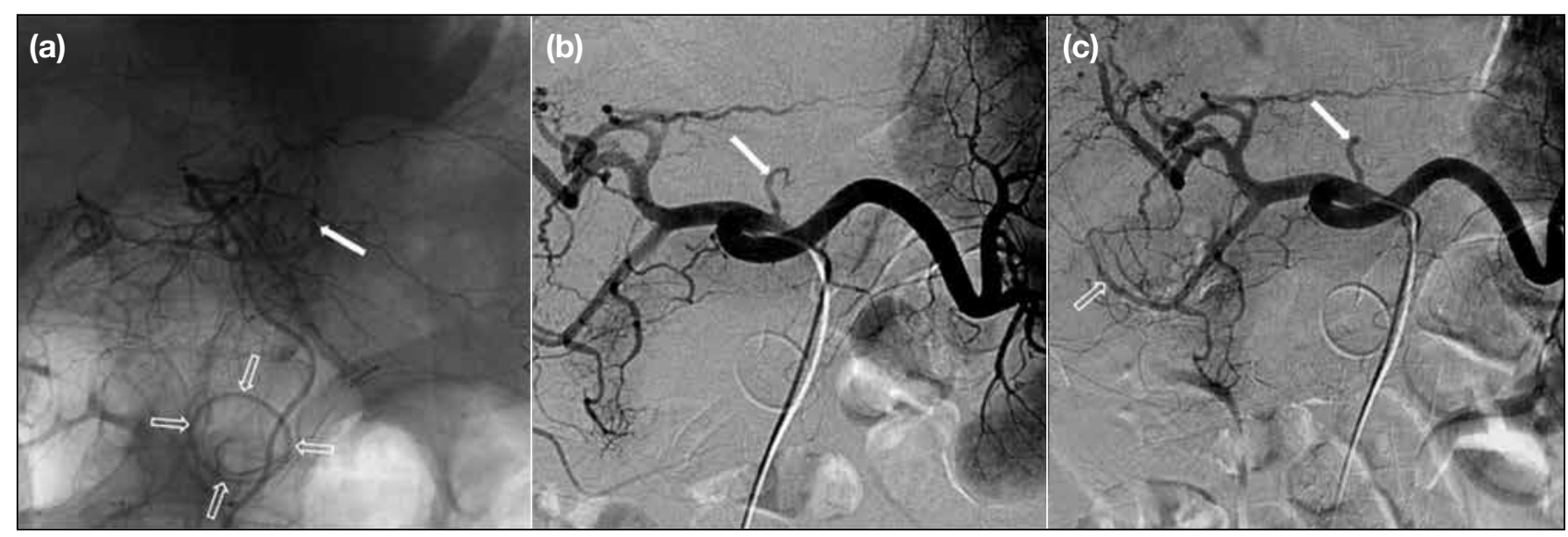

Figure 10. A 61-year-old male patient with gastric bleeding after endoscopic gastrostomy tube insertion. Gastric bleeding was difficult to control by endoscopic clipping as a result of multiple lacerations in the stomach. The patient did not show recurrent bleeding following embolisation and was stabilised. (a) Left gastric artery (LGA) angiography could not identify contrast extravasation. The LGA was embolised using Gelfoam particles. Endoscopic haemoclips (arrow) and an internal bumper of the endoscopic gastrostomy tube (open arrows) are noted. (b) Post-embolisation celiac angiography showing an obstructed proximal LGA (arrow) without contrast extravasation. (c) Bleeding recurred 8 days after embolisation of the LGA. Celiac angiography showing an obstructed LGA (arrow) but no active contrast extravasation. The right gastroepiploic artery (open arrow) was embolised preventatively using Gelfoam particles.

\section{OUTCOMES}

In a review by Loffroy et $\mathrm{al}^{6}$ of 15 studies (involving 819 patients, mean age 65 years), the technical success rate of endovascular embolisation of intractable nonvariceal UGIB was 93\%. Endoscopic haemostasis had failed in $99 \%$ of the patients. The causes for the failure of TAE to control UGIB included difficult vascular anatomy, arterial dissection, vasospasm, misinterpretation of angiography findings, multiple bleeding sites, and haemorrhage from malignant processes. The majority of the patients in that series who underwent TAE had significant co-morbidities and high levels of risk associated with operative intervention. Active contrast extravasation was observed at the time of TAE in only $54 \%$ of patients. Consequently, $46 \%$ of the patients underwent embolisation, guided by either 
endoscopy findings or clip placement around the area of the bleeding vessel. ${ }^{6}$ The clinical success rate was $67 \%$ in patients who underwent technically successful embolisation. Possible predictors of re-bleeding were the presence of multiple or large duodenal ulcers, longer time to angiography, massive transfusion requirements, previous surgery, bleeding secondary to trauma, cancer-associated bleeding, the use of coils as the sole embolic agent, gastritis, coagulopathy, and multi-organ failure. ${ }^{6,21,22}$ Continued bleeding was observed in $33 \%$ of patients, but almost half of those patients responded to repeat embolisation. Finally, $20 \%$ of the patients required open surgical intervention for definitive management of bleeding. ${ }^{6}$ The overall 30 -day mortality rate was $28 \%$, with bleeding being the underlying cause of death in most cases. ${ }^{6,24}$ The presence of uncorrectable coagulopathy was the most significant predictive factor for recurrent bleeding and mortality. ${ }^{23}$ Other significant predictive factors included older age, cirrhosis, oncologic disease, multiple organ failure, and frequent corticosteroid treatment. $^{23}$

\section{COMPLICATIONS}

Periprocedural complications occur with the same frequency in TAE as in other endovascular interventions. These complications, which often have no clinical consequences and are mostly preventable, include haematoma, pseudoaneurysm, arterial dissection, contrast allergic reactions, and nephrotoxicity. ${ }^{21-23} \mathrm{TAE}$ for UGIB is considered safe because of the abundant collateral blood supply to the stomach and duodenum. The risk of ischaemic complications increases when collateral blood supplies are damaged by an earlier surgical procedure of the upper abdomen, radiotherapy, severe atherosclerosis, or when liquid embolic agents or tiny particulate agents permeate far into the vascular bed..$^{1,21-23,50}$ Duodenal strictures resulting from ischaemia after embolisation are rare and have been reported in $<7 \%$ of cases. ${ }^{39,50}$ Other rare complications include unintentional embolisation of the main hepatic artery resulting in liver failure. ${ }^{23}$ The overall complication rate is approximately $9 \% .^{23}$

\section{CONCLUSION}

Management of acute nonvariceal UGIB remains a challenge. A multidisciplinary approach involving skilled endoscopists, intensive care specialists, experienced upper GI surgeons, and interventional radiologists is required. For the past three decades, the techniques and devices used for endovascular treatment of acutely haemorrhagic patients have significantly improved.
The gold standard for patients who fail endoscopic haemostasis is now TAE, which is widely accepted as a safe and effective treatment for life-threatening acute nonvariceal UGIB. Endovascular embolisation may be sufficient even for the most gravely ill patients who are not candidates for surgical treatment, even when angiography cannot visualise active contrast extravasation during empiric embolisation. Interventional radiologists should be aware of the technical and clinical factors that affect outcomes following embolotherapy. Embolisation should be performed as early as possible after the onset of bleeding with concurrent correction of coagulopathy. In addition, careful selection of the appropriate embolic agents according to the characteristics of the bleeding vessel and the patient's circumstances may improve overall technical and clinical outcomes.

\section{REFERENCES}

1. Walker TG. Acute gastrointestinal hemorrhage. Tech Vasc Interv Radiol. 2009;12:80-91.

2. Green BT, Rockey DC. Lower gastrointestinal bleeding management. Gastroenterol Clin North Am. 2005;34:665-78.

3. Abdel-Aal AK, Bag AK, Saddekni S, Hamed MF, Ahmed FY. Endovascular management of nonvariceal upper gastrointestinal hemorrhage. Eur J Gastroenterol Hepatol. 2013;25:755-63.

4. Frisoli JK, Sze DY, Kee S. Transcatheter embolization for the treatment of upper gastrointestinal bleeding. Tech Vasc Interv Radiol. 2004;7:136-42.

5. Huang CS, Lichtenstein DR. Nonvariceal upper gastrointestinal bleeding. Gastroenterol Clin North Am. 2003;32:1053-78.

6. Loffroy R, Rao P, Ota S, De Lin M, Kwak BK, Geschwind JF. Embolization of acute nonvariceal upper gastrointestinal hemorrhage resistant to endoscopic treatment: results and predictors of recurrent bleeding. Cardiovasc Intervent Radiol. 2010;33:1088100.

7. Zurkiya O, Walker TG. Angiographic evaluation and management of nonvariceal gastrointestinal hemorrhage. AJR Am J Roentgenol. 2015;205:753-63.

8. Lee EW, Laberge JM. Differential diagnosis of gastrointestinal bleeding. Tech Vasc Interv Radiol. 2004;7:112-22.

9. Mamdani M, Juurlink DN, Kopp A, Naglie G, Austin PC,Laupacis A. Gastrointestinal bleeding after the introduction of COX 2 inhibitors: ecological study. BMJ. 2004;328:1415-6.

10. Jutabha R, Jensen DM. Management of upper gastrointestinal bleeding in the patient with chronic liver disease. Med Clin North Am. 1996;80:1035-68.

11. Llach J, Elizalde JI, Guevara MC, Pellisé M, Castellot A, Ginès A, et al. Endoscopic injection therapy in bleeding Mallory-Weiss syndrome: a randomized controlled trial. Gastrointest Endosc. 2001;54:679-81.

12. Morales P, Baum AE. Therapeutic alternatives for the MalloryWeiss tear. Curr Treat Options Gastroenterol. 2003;6:75-83.

13. Romãozinho JM, Pontes JM, Lérias C, Ferreira M, Freitas D. Dieulafoy's lesion: management and long-term outcome. Endoscopy. 2004;36:416-20.

14. Sone Y,Kumada T, Toyoda H, Hisanaga Y,Kiriyama S, Tanikawa M. Endoscopic management and follow up of Dieulafoy lesion in the upper gastrointestinal tract. Endoscopy. 2005;37:449-53.

15. Meyer CT, Troncale FJ, Galloway S, Sheahan DG. Arteriovenous 
malformations of the bowel: an analysis of 22 cases and a review of the literature. Medicine (Baltimore). 1981;60:36-48.

16. Cumpa EA, Stevens R, Hodgson K, Castro F. Primary aortoenteric fistula. South Med J. 2002;95:1071-3.

17. Chapman WC, Abecassis M, Jarnagin W, Mulvihill S, Strasberg SM. Bile duct injuries 12 years after the introduction of laparoscopic cholecystectomy. J Gastrointest Surg. 2003;7:412-6.

18. Loffroy R, Guiu B, Cercueil JP, Lepage C, Cheynel N, Steinmetz E, et al. Transcatheter arterial embolization of splenic artery aneurysms and pseudoaneurysms: short- and long-term results. Ann Vasc Surg. 2008;22:618-26.

19. Gomes AS, Lois JF, McCoy RD. Angiographic treatment of gastrointestinal hemorrhage: comparison of vasopressin infusion and embolization. AJR Am J Roentgenol. 1986;146:1031-7.

20. ParenteF,Anderloni A,Bargiggia S,Imbesi V,TrabucchiE,BarattiC, et al. Outcome of non-variceal acute upper gastrointestinal bleeding in relation to the time of endoscopy and the experience of the endoscopist: a two-year survey. World J Gastroenterol. 2005; 11:7122-30.

21. Shin JH. Recent update of embolization of upper gastrointestinal tract bleeding. Korean J Radiol. 2012;13 Suppl 1:S31-9.

22. Shin JH. Refractory gastrointestinal bleeding: role of angiographic intervention. Clin Endosc. 2013;46:486-91.

23. Valek V, Husty J. Quality improvement guidelines for transcatheter embolization for acute gastrointestinal nonvariceal hemorrhage. Cardiovasc Intervent Radiol. 2013;36:608-12.

24. Loffroy R, Favelier S, Pottecher P, Estivalet L, Genson PY, Gehin S, et al. Transcatheter arterial embolization for acute nonvariceal upper gastrointestinal bleeding: indications, techniques and outcomes. Diagn Interv Imaging. 2015;96:731-44.

25. Palmer K. Management of haematemesis and melaena. Postgrad Med J. 2004;80:399-404.

26. Kovacs TO, Jensen DM. Recent advances in the endoscopic diagnosis and therapy of upper gastrointestinal, small intestinal, and colonic bleeding. Med Clin North Am. 2002;86:1319-56.

27. Artigas JM, Marti M, Soto JA, Esteban H, Pinilla I, Guillén E. Multidetector CT angiography for acute gastrointestinal bleeding: technique and findings. Radiographics. 2013;33:1453-70.

28. Geffroy Y, Rodallec MH, Boulay-Coletta I, Jullès MC, Ridereau-Zins C, Zins M. Multidetector CT angiography in acute gastrointestinal bleeding: why, when, and how. Radiographics. 2011;31:E35-46.

29. Soto JA, Park SH, Fletcher JG, Fidler JL. Gastrointestinal hemorrhage: evaluation with MDCT. Abdom Imaging. 2015;40:993-1009.

30. Loffroy R, Guiu B, D’Athis P, Mezzetta L, Gagnaire A, Jouve JL, et al. Arterial embolotherapy for endoscopically unmanageable acute gastroduodenal hemorrhage: predictors of early rebleeding. Clin Gastroenterol Hepatol. 2009;7:515-23.

31. Walsh RM, Anain P, Geisinger M, Vogt D, Mayes J, GrundfestBroniatowski S, et al. Role of angiography and embolization for massive gastroduodenal hemorrhage. J Gastrointest Surg. 1999;3:61-5.

32. Krüger K, Heindel W, Dölken W, Landwehr P, Lackner K. Angiographic detection of gastrointestinal bleeding. An experimental comparison of conventional screen-film angiography and digital subtraction angiography. Invest Radiol. 1996;31:451-7.

33. Song JS, Kwak HS, Chung GH. Nonvariceal upper gastrointestinal bleeding: the usefulness of rotational angiography after endoscopic marking with a metallic clip. Korean J Radiol. 2011;12:473-80.
34. Eriksson LG, Sundbom M, Gustavsson S, Nyman R. Endoscopic marking with a metallic clip facilitates transcatheter arterial embolization in upper peptic ulcer bleeding. J Vasc Interv Radiol. 2006;17:959-64.

35. Padia SA, Geisinger MA, Newman JS, Pierce G, Obuchowski NA, Sands MJ. Effectiveness of coil embolization in angiographically detectable versus non-detectable sources of upper gastrointestinal hemorrhage. J Vasc Interv Radiol. 2009;20:461-6.

36. Defreyne L, Vanlangenhove P, Decruyenaere J, Van Maele G, De Vos M, Troisi R, et al. Outcome of acute nonvariceal gastrointestinal haemorrhage after nontherapeutic arteriography compared with embolization. Eur Radiol. 2003;13:2604-14.

37. Aina R, Oliva VL, Therasse E, Perreault P, Bui BT, Dufresne MP, et al. Arterial embolotherapy for upper gastrointestinal hemorrhage: outcome assessment. J Vasc Interv Radiol. 2001;12:195-200.

38. Lenhart M, Paetzel C, Sackmann M, Schneider H, Jung EM, Schreyer AG, et al. Superselective arterial embolisation with a liquid polyvinyl alcohol copolymer in patients with acute gastrointestinal haemorrhage. Eur Radiol. 2010;20:1994-9.

39. Lang EV, Picus D, Marx MV, Hicks ME. Massive arterial hemorrhage from the stomach and lower esophagus: impact of embolotherapy on survival. Radiology. 1990;177:249-52.

40. Encarnacion CE, Kadir S, Beam CA, Payne CS. Gastrointestinal bleeding: treatment with gastrointestinal arterial embolization. Radiology. 1992;183:505-8.

41. Miller M Jr., Smith TP. Angiographic diagnosis and endovascular management of nonvariceal gastrointestinal hemorrhage. Gastroenterol Clin North Am. 2005;34:735-52.

42. Park JH, Kim HC, Chung JW, Jae HJ, Park JH. Transcatheter arterial embolization of arterial esophageal bleeding with the use of N-butyl cyanoacrylate. Korean J Radiol. 2009;10:361-5.

43. Lee CW, Liu KL, Wang HP, Chen SJ, Tsang YM, Liu HM. Transcatheter arterial embolization of acute upper gastrointestinal tract bleeding with N-butyl-2-cyanoacrylate. J Vasc Interv Radiol. 2007;18:209-16.

44. Mine T, Murata S, Nakazawa K, Onozawa S, Ueda T, Miyauchi M, et al. Glue embolization for gastroduodenal ulcer bleeding: contribution to hemodynamics and healing process. Acta Radiol. 2013;54:934-8.

45. Jae HJ, Chung JW, Jung AY, Lee W, Park JH. Transcatheter arterial embolization of nonvariceal upper gastrointestinal bleeding with N-butyl cyanoacrylate. Korean J Radiol. 2007;8:48-56.

46. Kim JH, Shin JH, Yoon HK, Chae EY, Myung SJ, Ko GY, et al. Angiographically negative acute arterial upper and lower gastrointestinal bleeding: incidence, predictive factors, and clinical outcomes. Korean J Radiol. 2009;10:384-90.

47. Poultsides GA, Kim CJ, Orlando R 3rd, Peros G, Hallisey MJ, Vignati PV. Angiographic embolization for gastroduodenal hemorrhage: safety, efficacy, and predictors of outcome. Arch Surg. 2008;143:457-61.

48. Loffroy R, Lin M, Thompson C, Harsha A, Rao P. A comparison of the results of arterial embolization for bleeding and non-bleeding gastroduodenal ulcers. Acta Radiol. 2011;52:1076-82.

49. Arrayeh E, Fidelman N, Gordon RL, LaBerge JM, Kerlan RK Jr, Klimov A, et al. Transcatheter arterial embolization for upper gastrointestinal nonvariceal hemorrhage: is empiric embolization warranted? Cardiovasc Intervent Radiol. 2012;35:1346-54.

50. Loffroy R, Guiu B. Role of transcatheter arterial embolization for massive bleeding from gastroduodenal ulcers. World J Gastroenterol. 2009;15:5889-97. 